\title{
General Characteristics of the Cells Transformed in vitro by Human Adenovirus Type 12
}

\author{
Toshihisa Kusano and Isao Yamane \\ The Microbiology Division, Research Institute for Tuberculosis, \\ Leprosy and Cancer, Tohoku University, Sendai
}

From in vivo induced tumors by adenovirus typ 12 , four cell lines were established in vitro $(\mathrm{H}-1, \mathrm{H} 2-1, \mathrm{H} 2-2$ and $\mathrm{H}-4)$ and from the in vitro transformed foci in embryonal hamster brain tissue culture by the same virus, 7 lines were successfully subcultivated (HT-1, HT-2 so on). There was no gross differences in thoir characteristics. Morphologically they were tenacionsly adherent small epithelioid cells. They needed large inoculum to subculture in rubber stoppred culture system. Callular aggregations were frequently observed in the static culture conditions and calcium concentration suggested to bear it. The attempt to isolate the infectious virus from tumor cells and transformed cells at various passage levels has failed so far.

Cultivation of in vivo induced tumor cells by adenovirus type 12 demonstrated that the cultured cell population was heterogeneous during several passages, consisting of fibroblast-like and epithelioid or polygonal cells. ${ }^{1-3}$ On continued subcultures, the proportion of fibroblastic cell decreased and they eventually disappeared. Epithelioid cells were liable to aggregate and grew in the form of isles, and after several subcultures the cells sometimes formed large ball-like aggregates which eventually floated free in the medium. Kitamura et al. ${ }^{2}$ reported that the serum component of the medium had an influence on the cell aggregation and Freeman et al. ${ }^{4}$ demonstrated that it was affected by calcium ion concentration of the medium. So far, all attempts to isolate an infectious virus from adenovirus induced hamster tumors have been unsuccessful. However, the findings that the most animals with primary or transplanted tumors develop adenovirus type 12-specific complement fixing antigens suggest the presence of the viral genome in some form. From the foci of cells transformed in vitro by adenovirus type 12 , successive cultures were obtained. In the present report, the morphology and growth characteristics of these cells and an attempt to demonstrate the virus are described. Transplantability of transformed cells will be described elsewhere ${ }^{5}$ and also karyotype analysis will be reported separately.

\section{Materials and Methods}

Successive culture of the transformed cells. The foci of transformed cells were

Received for publication, January 23, 1967. 
allowed to reach 1 to $2 \mathrm{~mm}$ in diameter before they were transferred. Individual foci were picked up with caution not to contaminate one another by a sterilized planting loop into the tubes. Sometimes it was difficult to obtain transfer successfully. In such cases, transformed cells were mixed up with normal brain cell cultures. The normal cell cultures were able to support the growth of a small number of transformed cells. By this method a small number of transformed cells proliferated rapidly. After several passages normal cells deteriorated, and confluent colonies of transformed cells were obtained.

Brain cell cultures of newborn hamsters. Cells were prepared by explant culture of brain tissues of 24 to 48 hour old golden hamsters (Mesocrisetus auratus) from random bred strains. Details of the procedure were described elsewhere. ${ }^{5}$ The time necessary for doubling cell numbers was checked through subcultivation procedure similar to that of Todaro et $a l .^{6}$ and the congenital growth properties were compared with those of in vitro transformed cells.

Growth medium. Eagle's minimal essential medium (MEM) supplemented with $20 \%$ bovine serum was used at first, subsequently the serum proportion was reduced to $15 \%$. All sera were inactivated at $56^{\circ} \mathrm{C}$ for 30 minutes. The medium contained $80 \mathrm{mg}$ of Kanamycin per liter as a decontaminant.

Test of the effect of calcium ion on the aggregate formation of in vitro transformed cells. To test the aggregate formation by calcium ion, transformed cells were cultured in Eagle's MEM without calcium chloride, supplemented with $20 \%$ bovine serum. In this medium the cells grew in stretched form, and the culture was replaced with the medium which contained 5 and $10 \mathrm{mM}$ calcium chloride. To test the effect of another divalent cation, magnesium chloride was examined at the same concentration.

Superinfection test. HT-2 cells at the 21 st passage were inoculated with a strain adenovirus type 12 with a titer of $10^{2} \mathrm{TCID}_{50}$ per $\mathrm{ml}$ on $\mathrm{KB}$ cells. Cytological observations were made and supernatant fluid and cells were titered for virus separately, the latter after being frozen and thawed 6 times. Virus assay was carried out on KB cells fed Eagle's MEM plus $1 \%$ calf serum.

\section{Results}

Establishment of the adenovirus type 12 in vitro. Tumor tissues from 3 tumorbearing hamsters were surgically excised 35 days after the virus was intraperitoneally inoculated and these tissue explants were cultured in vitro. In several days of cultivation many batches of transparent epithelioid cells appeared in the stromal fibroblastic cells in all cultures. They were dispersed for the subcultivation with $0.01 \%$ pronase plus $0.02 \%$ EDTA. Cell seeds of more than $5 \times 10^{5}$ cells per $\mathrm{ml}$ were necessary for successful culture of the tumor cells in rubber stoppered bottle culture system. Each cell line will be referred to as H1-2, H2-1, H2-2 and $\mathrm{H} 4$, respectively. All cell lines were similar in their morphology, growth properties and other features. Subsequently, these characteristics were comparable with those of cells transformed in vitro. 
Subcultivation of transformed cells. The morphology of the surrounding normal cells was somewhat different from that of primary cultures of tumor cells developing in vivo because their cellular construction in which the foci and tumors developed was different. In any way, surrounding cells deteriorated in both cultures and could not be detected after several passages. At that time, confluent growth of transformed cells and tumor cells was established. These cells were so adhesive to one another that they formed islands on the glass surface. At the same time a tendency to form large aggregates became prominant. Morphologically they were composed of small epithelioid cells with large nuclei containing several nucleoli. Subsequently, cells from some foci were established and referred to as transformed cell line of hamster origin (HT-2, -3 and so on) (Fig. 1).

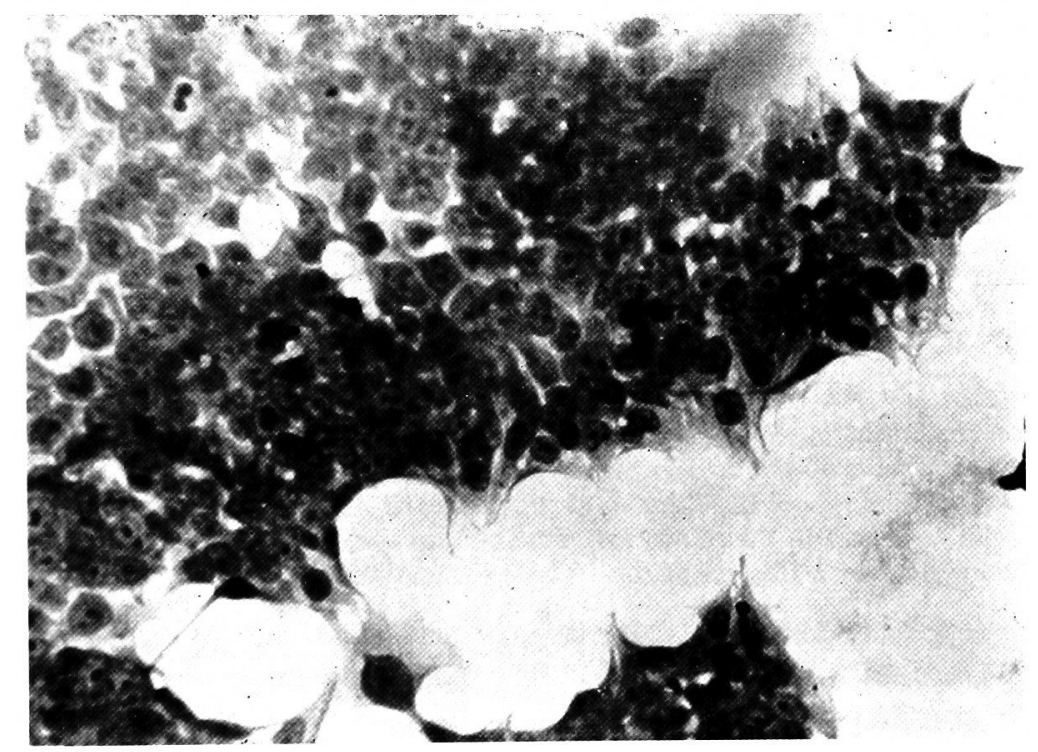

Fig. 1. In vitro transformed cells in culture, stained with Giemsa. $\times 800$.

Growth characteristics. HT cells were cultured mainly in the rubber stoppered culture bottles. But with these culture system it was difficult to maintain the cells in good condition when a small number of cells was seeded, whereas cultures were luxuriant in $5 \% \quad \mathrm{CO}_{2}$ incubator. Fig. 2 shows the growth of the serial cultures which were examined from 29 to 41 passages of HT-2 line and from 5 to 12 passages of HT-3. To check the growth, culture bottles $(45 \times 85 \times$ $25 \mathrm{~mm}$ ) were dispensed with $5 \mathrm{ml}$ of medium. Some of the culture bottles were made air tight by rubber stoppers and others were loosely capped with aluminium foil. In the latter case, air was allowed to enter the bottles. An appropriate number of cells were seeded and all the cultures were incubated at $37^{\circ} \mathrm{C}$ in a ' $\mathrm{CO}{ }_{2}$ incubator'. The dotted lines indicate the cellular growth with the former system and solid lines with the latter system (Fig. 2). As a rule the cellular growth was 

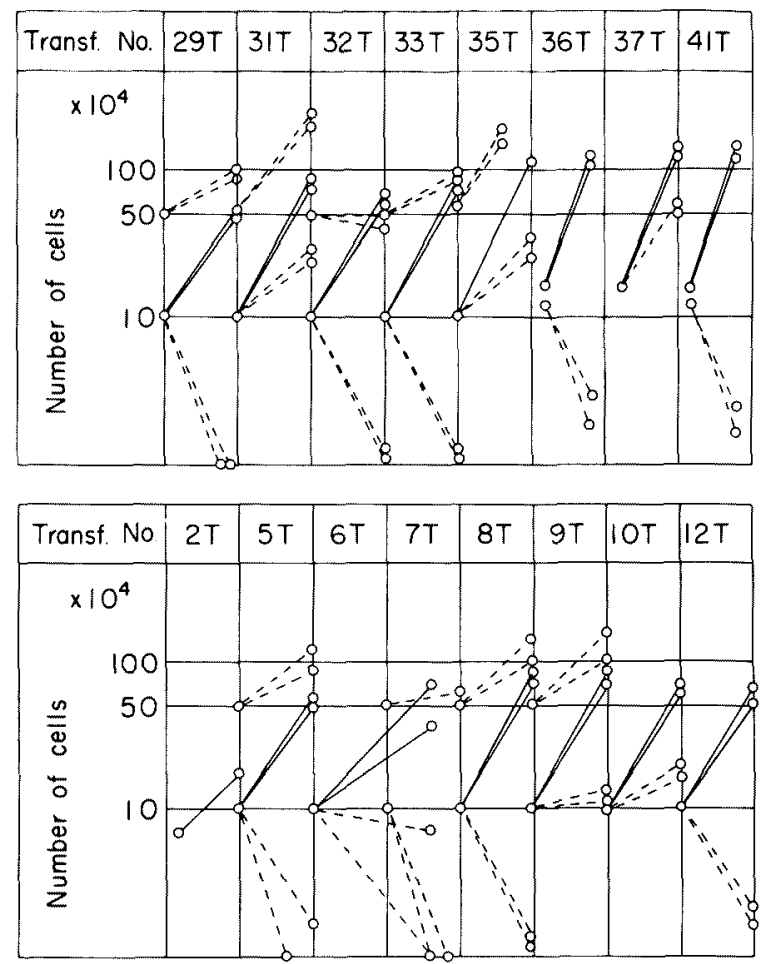

Fig. 2. Growth curve of cells transformed by adenovirus type 12 in vitro. The upper figure is the growth curve of HT-2 line and the lower HT-3 line. The dotted lines indicate the cellular growth in the rubber stoppered culture system and solid lines in the open culture system in a $\mathrm{CO}_{2}$ incubator. The cells were transfered every 5 days.

rarely observed in the closed gaseous culture system employing an inoculum size of $10^{5}$ cells $/ \mathrm{ml}$, and more than $5 \times 10^{5}$ cells $/ \mathrm{ml}$ were necessary as inoculum to make the transfer of the culture possible. However, the bottle culture loosely sealed with aluminium foil in the ' $\mathrm{CO}_{2}$ incubater' enabled $10^{5}$ cells to grow into a confluent cellular sheet.

Establishment of normal brain culture and the growth pattern of transformed cells. Two cell lines were obtained from cultures of the newborn hamster brain and the growth curve of one cell line was shown in Fig. 3. Growth index was obtained as follows: $10^{5}$ cells per $\mathrm{ml}$ were seeded into a Petri dish containing $3 \mathrm{ml}$ of medium. Growth during the first 24 hours after inoculation was neglected and increase for 48 hours after the first 24 hours were calculated. Primarily the normal brain cell cultures consisted of many types of actively proliferating cells. After several passages, growth rate decreased and cells which had long fibrous processes became predominent. This type of cells seemed not to proliferate and eventually was lost from the cultures, and thinly stretched cells remained, which subsequently ceased growth and could not be transferred for several months. Then all the cultures slowly resumed the growth, and cell lines could be established. The pattern of 


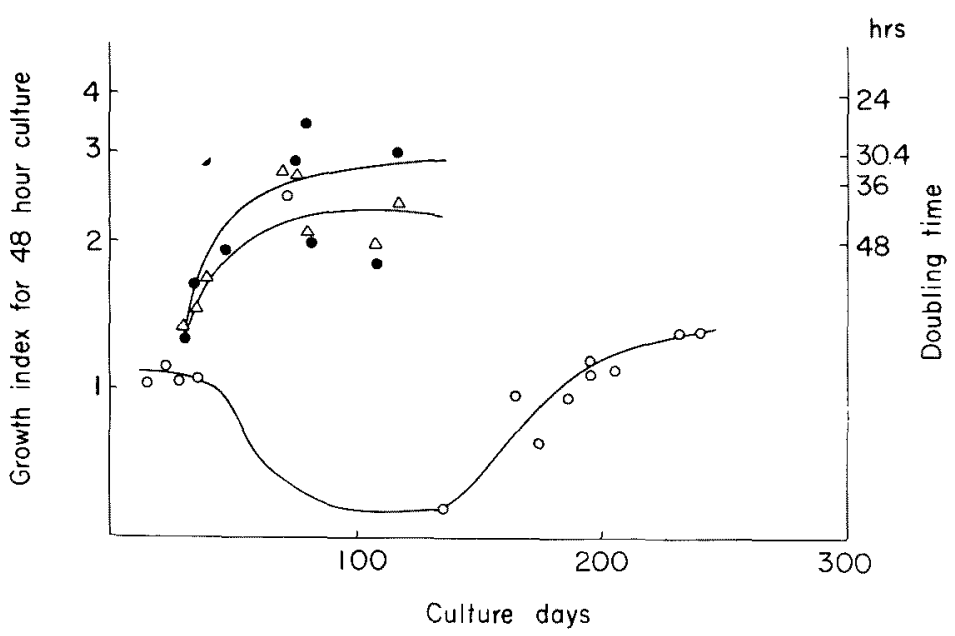

Fig. 3. Growth curve of cells transformed in vitro by A-12 and of normal brain cells.

-.-.-: HT-3 cells

$-\infty-\Delta-$ : HT -4 cells

-o-: Normal brain cells

establishment of the transformed cells were different from that of normal brain cells as shown in Fig. 3. The growth rate of $\mathrm{HT}$ cells was higher than that of normal cultures since the time of its early transfers, though the doubling time of HT cells varied from 24 to 50 hours, and even when the normal culture entered into the static phase, HT cells grew constantly.

Effect of calcium ions. In serial cultures of in vitro transformed cells, ball-like aggregates were observed after several transfers. This phenomenon seemed to occur after intermingled normal cells were segregated. It was frequently observed through many passages in Eagle's MEM at a calcium level of $1.8 \mathrm{mM}$. However, long time cultivation of $\mathrm{HT}-2$ line revealed that the property to form aggregates was gradually lost, and after 60 transfers (about 10 months) aggregate formation occurred rarely. But at the eary passage time this phemomenon was observed in all cell lines from tumor cell cultures and all lines from transformed cells. In calcium free Eagle's medium supplemented with 20 per cent bovine serum, adherency of cells to one another became indistinct, and the cells grew well on glass surface in stretched form. Aggregate formation was examined by adding $5 \mathrm{mM}$ and $10 \mathrm{mM}$ calcium chloride to HT-3 line at 17 to 25 passages and to HT-4 line at 12 to 20 passages. The cells of both lines were growing in monolayer. Twenty-four hours after addition of calcium chloride, retraction of the monolayer culture was observed in its several portions, and the number of aggregates gradually increased. The aggregates first attached to glass and then became floated free in the medium (Fig. 4). To examine whether this phenomenon may occur in other cell cultures, 


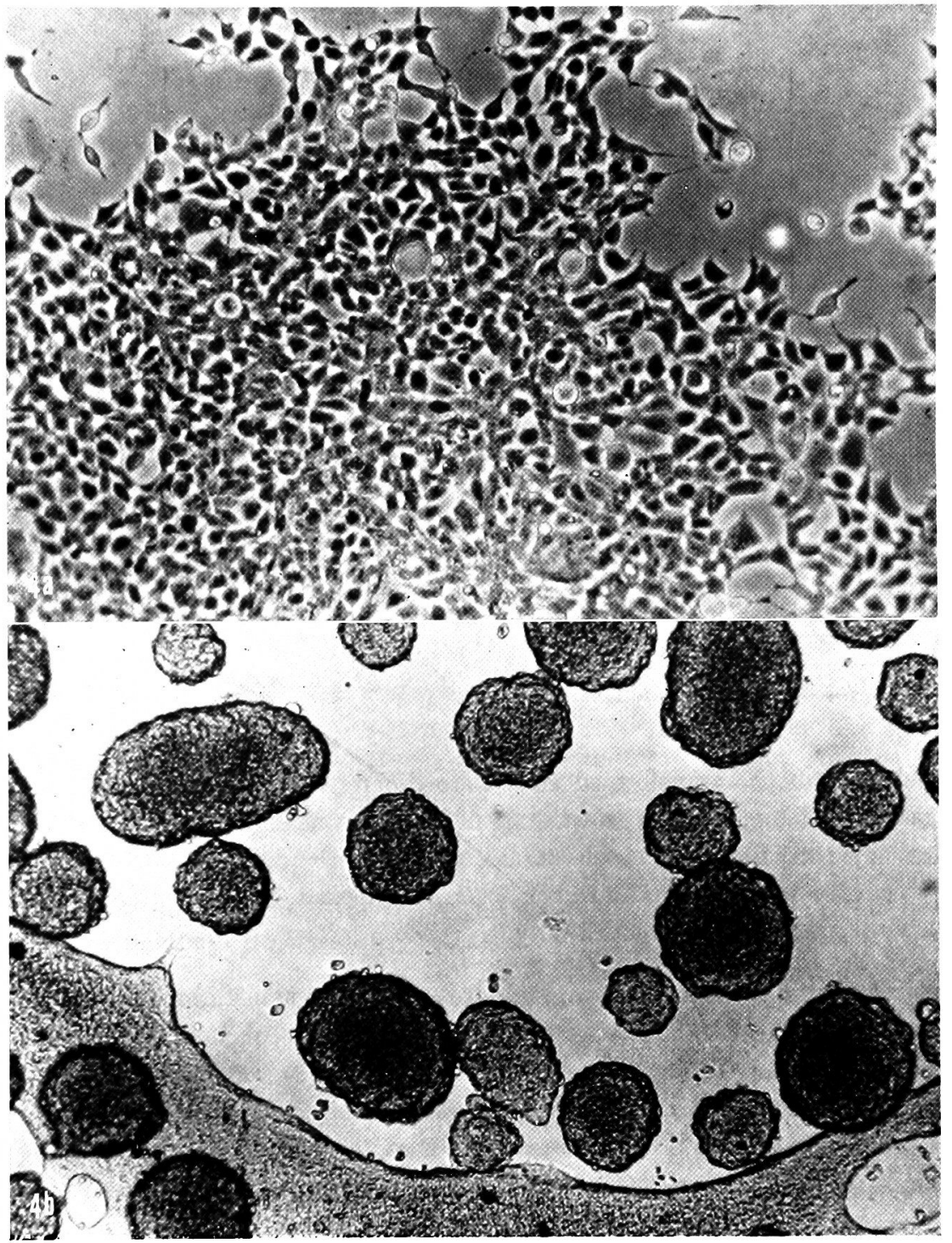

- Fig. 4. Aggregates formation of the transformed cells.

a) HP 3 in calcium free MEM plus 20 per cent bovine serum. $\times 400$.

b) Aggregate formation 2 days after the addition of $5 \mathrm{mM}$ calcium chloride into the above culture. $\times 75$.

cultures of the normal hamster brain cell at the 2nd and 24th passages, HeLa cells and the lung cells of newborn hamsters at the 104th passage established in our labaratory were examined; but no aggregation was observed. To test the effect of another divalent cation, magnesium chloride was added to the above cultures. However, no aggregates were observed (Table 1). 
TABLE 1. Ball-like aggregate formation of cells transformed in vitro by adenovirus type 12 by calcium ion

\begin{tabular}{c|c|c|c|c|c|c}
\hline Cells & $\mathrm{HT}-3(17)$ & $\mathrm{HT}-4(12)$ & $\mathrm{HB}-23(2)$ & $\mathrm{HB}-1(24)$ & $\mathrm{HeLa}$ & $\mathrm{BHL}(\mathrm{104})$ \\
\hline $\mathrm{CaCl}_{2}$, conc. & & & & & \\
\hline ca. $\begin{array}{c}0.7 \mathrm{mM} \\
5\end{array}$ & - & - & - & - & - & - \\
10 & + & $H$ & - & - & - & - \\
*HT-3, -4 cells; A-12 in vitro transformed cell. \\
HB-12, -23 cells; Normal hamster brain cells. \\
BHL: Normal fibroblasts of the newborn hamster lung. \\
* Number between parentheses indicates transfer number in vitro.
\end{tabular}

Attempts to isolate the virus from tumor cells cultured and cells transformed in vitro. Several methods were examined in attempts to demonstrate virus production. 1) Inoculation of supernatant fluids and lyzed cells: At several different passage levels, about $1 \times 10^{6}$ of cells per ml were cultured in a Petri dish containing $3 \mathrm{ml}$ of the medium supplemented with bovine serum to 2 to 5 per cent and maintained for a week. Then they were disrupted by 3 cycles of freezing and thawing, and supernatant of culture which was centrifuged for 15 minutes at $1,000 \mathrm{rpm}$ was assayed by inoculation of 0.25 and $0.1 \mathrm{ml}$ per tube of $\mathrm{KB}$ cells. 2) Electron microscopical observation: HT-2 line at the 20th passage was examined for virus particles by electron microscopy. 3) Mixed culture of tumor cells on transformed cells with KB or PS cells: Tumor cells or transformed cells were mixed with virus-sensitive cells and subcultured together according to Gerber's method. They were in direct contact with virus-sensitive cells and subcultured for several passages. The

TABLE 2. Direct and indirect methods employed in aftempts to detect adenovirus type 12 in tumor cell culture

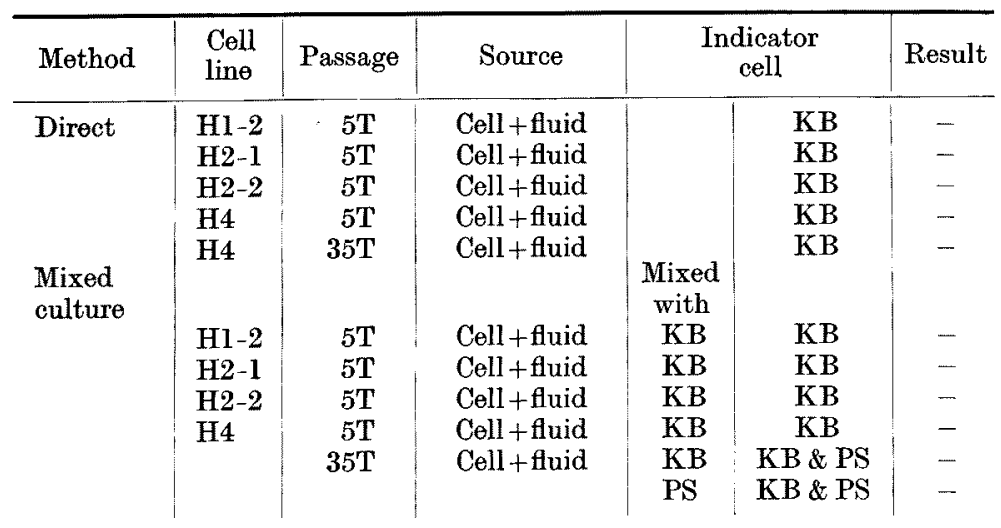

Final reading on the $7-9$ th days. $\quad 2-5 \%$ bovine serum was used for test culture. Note: Cells in direct method and from mixed culture were frozen, thawed 3 times, and centrifuged at $1,000 \mathrm{rpm}$ for 15 minutes, and 0.25 and $0.1 \mathrm{ml}$ of the supernatant were inoculated to indicator cultures. 
TABLE 3. Attempt to induce virus production in transformed hamster cells

\begin{tabular}{l|c|c|c|c}
\hline $\begin{array}{c}\text { Inducing } \\
\text { agents }\end{array}$ & Dose & $\begin{array}{c}\text { Period of } \\
\text { treatment }\end{array}$ & Source & Result \\
\multicolumn{1}{c|}{ None } & & $\begin{array}{c}\text { No } \\
\text { treatment }\end{array}$ & Cell +fluid & - \\
Proflavin & $1-10 \mu \mathrm{g} / \mathrm{ml}$ & $6-8 \mathrm{hr}$ & $"$ & - \\
Acriflavin & $1-10 \mu \mathrm{g} / \mathrm{ml}$ & $24 \mathrm{hr}$ & $"$ & - \\
$\mathrm{H}_{2} \mathrm{O}_{2}$ & $10^{-3}-10^{-5} \mathrm{M}$ & $7 \mathrm{days}$ & $"$ & - \\
$\mathrm{Mitomyein} \mathrm{C}$ & $0.1-1 \mu \mathrm{g} / \mathrm{ml}$ & $7-24 \mathrm{hr}$ & $"$ & - \\
$4-\mathrm{NQ}$ & $10^{-5}-10^{-7} \mathrm{M}$ & $7 \mathrm{hr}$ & $"$ & -
\end{tabular}

Transformed cells used were HT-2 line (49-5l passages). Indicator cells were the 2nd human kidney cells. Cells were frozen-thawed 3 times, and centrifuged at 1,000 rpm for 15 minutes, and 0.25 and $0.1 \mathrm{ml}$ of supernatant were inoculated to indicator cells.

cultures were observed for $\mathrm{CPE}$ and their supernatant and lyzed cells were tested for the presence of infectious viruses (Table 4). 4) Attempts to induce virus production in transformed cells: HT-2 line from the 49th to 5lst passages were examined by the treatment of some inducers such as proflavin, acriflavin, $\mathrm{H}_{2} \mathrm{O}_{2}$, Mitomycin $\mathrm{C}$ and 4-nitro-quinoline $\mathrm{n}$-oxide. The cells were maintained for a week in maintenance medium after treatment and then its supernatant and lyzed cells were examined with highly sensitive human embryonal kidney cells (Table 3). By all methods examined no virus was detected in the tumor cell cultures and transformed cells. Further in vitro transformed cells were inoculated with adenovirus type 12 and studied for cytological changes, and intracellular and extracellular viruses. $\mathrm{KB}$ cells and secondary culture cells of the newborn hamster brain tissue were similarly inoculated with them and studied as control. No typical adenovirus CPE nor viral growth was demonstrable in either cells or supernatant fluid of cultures of in vitro transformed cells or of normal brain cells.

\section{Discussion}

The cells transformed in vitro seem to bear a striking resemblance in a number of their properties to in vivo induced tumor cells by the virus in culture. Morphologically they are small epithelioid cells and show selective advantage of growth and are piled up to multiple layers. However, crisscross or random orientation of cellular arrangement, which was thought as one of the prominent properties of transformed cells by polyoma ${ }^{7}$ viruse, was not demonstrated in the transformed cells by adenovirus type 12. This may suggest the difference of cells subject to malignant transformation by adenovirus from those by polyoma virus. So far, it was reported ${ }^{8}$ that tumor cells induced by adenovirus type 12 were sometimes difficult to culture successively. In the authors' experience a large number of cell seeds and frequent medium change made possible successful transfer by the rubber stoppered bottle culture system, whereas cultures in $5 \% \mathrm{CO}_{2}$ incubator could sustain 
the growth of a small number of cells. Calcium ion or $\mathrm{pH}$ adjustment could not improve the cultural condition in a closed culture system. The causes of this difference are not known as yet, but the nutritional or $\mathrm{CO}_{2}$ requirement of cultures are now under investigation.

The pattern of cellular growth in a long-term cultivation in vitro have been reported by many investigators, ${ }^{6,9,10}$ Many mammalian cells could be kept in a state of active proliferation for a various but definite period of time. Newborn hamster brain cells could proliferate actively for a month. Then they stopped the growth for several months, although they could resume the growth and cell lines could be established. On the contrary, the growth potential of transformed cells did not decline and seemed to gain the properties of established cells in early stage of transformation. Aggregate formation in monolayer culture of adenovirus induced tumor cells were first observed by Kitamura et al. ${ }^{2}$ and Freeman et al., ${ }^{4}$ who reported that the phenomenon was caused by calcium ion. The experiments on the calcium ion effect for the transformed cells revealed that clumping was consistent with the adenovirus induced tumor cells. HeLa cells and other cultures originating from hamster tissues exhibited no aggregation. The susceptibility of adenovirus induced tumor cells and transformed cells to calcium ion seems to be unique. An important characteristic of these cells is the production of virus specific complement fixing antigens, which strongly suggest the existence of viral genome within these cells in some form. However, the release of infective virus from adenovirus induced tumor cells has not been demonstrated so far. Our attempt did not either succeed in demonstrating infectious virus in tumor cells and in vitro transformed cells.

\section{References}

1) Barski, G. \& Cornefert, Fr. Culture in vitro des tumeurs pulmonaires de hamsters produites par l'adenovirus 12. Ann. Inst. Pasteur, 1964, 107, 109-114.

2) Kitamura, I., van Hoosier, G. L., Jr., Samper, L., Taylor, G. \& Trentin, J.J. Characteristics of human adenovirus type 12 induced hamster tumor cells in tissue culture. Proc. Soc. exp. Biol. Med., 1964, 116, 536-568.

3) Strohl, W.A., Rouse, H.C. \& Schlesinger, R.W. In vitro cultivation of malignant cells derived from adenovirus induced hamster tumors. Virology, 1963, 21, 513-516.

4) Freeman, A.E., Hollinger, S., Price, P.J. \& Calisher, C. The effect of calcium on cell lines derived from adenovirus type 12 induced tumors. Exp. Cell Res., 1965, 39, 259264.

5) Kusano, T. \& Yamane, I. Transformation in vitro of the embryonal hamster brain cells by human adenovirus type 12. Tohoku J. exp. Med., 1967, 92, 141-150.

6) Todaro, G.J. \& Green, H. Quantitative studies of the growth of mouse embryo cells in culture and their development into established lines. J. Cell Biol., 1963, 17, 299. 313.

7) Stoker, M. \& Macpherson. I. Studies on transformation of hamster cells by polyoma virus in vitro. Virology, 1961, 14, 359-370.

8) Lorans, G. \& Tournier, P. Une facteur de croissance nécessaire a la culture in vitro des callules de tumeurs chez le hamster par l'adenovirus 12. C.R. Acad. Sci. (Paris), 1964, 258, 386-388. 
9) Chang, R.S. A comparative study of the growth, nutrition, and metabolism of the primary and the transformed human cells in vitro. J. exp. Med., 1961, 113, 405-417.

10) Hayflick, L. \& Moorhead, P.S. The serial cultivation of human diploid cell strains. Exp. Cell Res., 1961, 25, 585-621. 